\title{
PROFESSIONAL DEVELOPMENT OF MATHEMATICS TEACHERS IMPLEMENTING PROBABILISTIC SIMULATIONS IN ELEMENTARY SCHOOL CLASSROOMS
}

\author{
LEANDRO DE OLIVEIRA SOUZA \\ Universidade Federal do Amazonas \\ olileo@ig.com.br \\ CELI ESPASANDIN LOPES \\ Universidade Cruzeiro do Sul \\ celilopes@uol.com.br \\ LUZINETE DE OLIVEIRA MENDONÇA \\ Universidade Cruzeiro do Sul \\ luzinete-mendonca@uol.com.br
}

\begin{abstract}
The inclusion of statistics and probability in the mathematics curriculum has always generated challenges to mathematics teachers of elementary schools. This article discusses activities that promote the professional development of such teachers. We present part of a doctoral research study of 16 teachers in which we discuss two case studies of teachers who planned teaching activities focusing on probabilistic simulations. Results demonstrated that the joint elaboration and discussion, within an educational space marked by collaboration, afforded teachers greater security when addressing the subject, and allowed them to develop new knowledge and ideas on teaching and learning statistics and probability. However, diverse pedagogical beliefs could drive different teachers' attitudes in classes and influence their focus while implementing their practices.
\end{abstract}

Keywords: Statistics education research; Lesson planning; Investigative activities; Case studies; Pedagogical beliefs; Pedagogical practices

\section{INTRODUCTION AND THEORETICAL BASIS}

Teaching is still challenged by the integration of statistical analysis with probability distributions and assumptions related to these models (Pfannkuch, 2005). Teachers have been reluctant to introduce probability in the last years of elementary school (10-14 years old). Serradó, Azcárate and Cardeñoso (2006) argue that such opposition is related to the fact that many teachers believe that probability is not an elementary issue, and also to the conventional and 'tough' way that textbooks address probability as unrelated to statistics.

Lopes (2003) points out the lack of teachers' knowledge of interrelations between probability and statistics, and of how such relations help with drawing inferences and making more reasonable decisions. Lajoie (1998) considers that the essence of a distribution lies in the clear link between statistics and probability. From this perspective, probabilistic thinking is strongly related to thinking about variation.

According to Pfannkuch (2005), there is a need for deeper research that would examine informal and formal reasoning about inferential statistics, and also for careful investigations about the best ways to empower students to make connections between probability and inferential statistics. In this context, we believe it is necessary to build on prior pedagogical education, so that teachers might expand their professional knowledge and develop new teaching approaches.

Statistics Education Research Journal, 13(2), 83-92, http://iase-web.org/Publications.php?p=SERJ C International Association for Statistical Education (IASE/ISI), November, 2014 
Thus, our goal for this study was to analyze the pedagogical actions of two teachers, who designed statistics lessons, implemented them and communicated their observations about the development of these teaching activities. The lessons were designed by teachers who were participants in a project of teacher professional development focused on the teaching of statistics and probability. From that, we aimed to get insight about how teachers' beliefs could influence their planning and practices in statistics classes.

\section{TEACHING THROUGH INVESTIGATIVE ACTIVITIES}

The development of students' statistical and probabilistic thinking can be made possible through a didactic approach, centered in investigative activities. From this perspective, it can be considered that activities involving simulations allow students to explore and/or apply mathematical and statistical concepts. Thus, each simulation or game (gambling) should trigger a series of questions (Marco, 2004).

A study published by Pierce and Chick (2011) suggests that teachers bring with them two different kinds of beliefs about the relationships between statistics, probability and inference. The first is that statistics is a particular mathematical activity, while the second is that statistics involves ways of thinking to make sense of the world to develop personal meanings. Moreover, according to Begg and Edwards (1999), teachers who present either of these views also believe that statistics can be easily manipulated to support personal views and particular interests. These pre-conceptions or pre-beliefs are likely to influence a teacher's approach in such way that teaching statistics might be taught as a science of guessing, a science of persuasion or a science of reasoning and interpretation.

The teaching activities prepared by teachers should lead students to mobilize concepts, organize procedures and develop a behavior that expands their ideas and views about mathematics, statistics and related concepts (Mendonça \& Lopes, 2013). In order to achieve this, the teacher must ask the students about their strategies, so a simulation or game would truly become a suitable environment for conceptual learning and (re)creation, rather than just a mechanical reproduction of the concepts (Marco, 2004).

Statistical inference is still often presented in undergraduate courses as a set of formal tests and procedures, through approaches which show only the descriptive side of this science in which information contained in sample data is used to estimate the values of the respective population parameters or to check claims made regarding the values of a population (Paparistodemou \& Meletiou-Mavrotheris, 2008; Stohl, 2005). Such a view of inference is rejected by mathematics teachers in the middle school, as such procedures do not make any sense to their students. Instead, teachers attempt to facilitate the learning of the content by teaching measurement, probability and interpretation of graphs as separate topics.

However, when encountering a pedagogical system that emphasizes investigative approaches, teachers might have doubts on how to proceed in their classes; for example, "Which theme or game and learning objective should be chosen in order to make the lesson more significant? How should the situation be addressed, in order to give new information to my students? How could my students be involved in a discussion about a real situation that makes intuitive reasoning necessary? How do I ensure the empirical construction of new concepts? Which intervention will help my students build new knowledge?"

In order to address such concerns, we believe that teachers should be involved in an environment in which investigative activities and simulations are developed. Why is it so important to teach statistics through investigative activities, experiments or simulations? One reason is the difficulties that students have in understanding the law of large numbers (Ireland $\&$ Watson, 2009). Simulations and investigations can help students to become aware of the application of probability in statistical environments.

The fact that students and teachers are able to calculate theoretical probability does not mean that they can understand the concepts when acting in statistical environments. There is a need to allow students and teachers to investigate fundamental ideas such as 'fair', 'equally likely', and 'random' in small and large numbers of trials. 
Mathematics teachers, through investigative processes, must be prepared to support, lead, interfere and, when necessary, build strategies, so that students may understand any mistakes in their own mathematical and statistical solutions. In this process, teachers should refrain from influencing students by expressing their opinion about students' interpretations and argumentation. Questions should be presented in a way that would provoke students and lead them to reflect and seek consistent concepts and procedures. The development of investigative activities requires a particular form of argumentation, which presents challenging questions related to the learning objectives.

Questions can lead students to construct procedures and mobilize concepts in order to solve problems that they face. We believe that this 'intervention model' helps students to develop their statistical and probabilistic thought. Moreover, this experience is essential to the development of students' argumentative, intuitive and discursive capacities.

To help teachers in developing such an approach, a training phase to identify collaborative ideas could be useful. After that, a planning phase to create lessons and interventions for their classes can provide teachers with data to understand students' reasoning. When developing their own teaching activities, teachers will be more able to anticipate difficulties that their students might have; thus, they will be better prepared to promote their students' learning.

The following section describes the methodology used in this research. The overall professional development sought to assist a group of teachers to reflect on and develop their teaching approaches. However, our aim in this paper is to discuss how teachers are influenced by their beliefs when they are planning and implementing statistics lessons, using a contrasting pair of case studies of two specific teachers.

\section{METHODOLOGY}

The research reported in this paper is set within the context of a larger project of teacher professional development focused on the teaching of statistical inquiry. One of the aims of our research project was to involve teachers in a process of development focused on the construction of collective knowledge grounded in the cognitive processes emerging from individual experiences.

We follow Imbernón's (2010) ideas, arguing that an improvement of teacher knowledge demands a better environment for teaching and learning with collaboration, esteem and participation. Imbernón states that professional development must entertain an open flux of ideas, independently of popularity. The learning experience must increase individual teachers' confidence by drawing on the collective capacity of teachers to find, plan and solve problems in such ways that they might learn from different solutions. The fact that the majority of teachers have not studied pedagogical approaches to teaching probability and statistics implies that they need to be immersed in a process of experimentation in which the materials should not simply be offered to them, but rather built and discussed by them.

Participants in the overall project were 16 mathematics-specialized teachers of the last years of elementary school. They attended 11 weekly meetings of two and a half hours each. Meetings were divided into three phases: workshop, planning and communication. The workshop phase consisted of four meetings in which teachers had their first contact with investigative approaches and technological resources for statistics teaching (Fathom software and free internet apps). The second phase was also divided into four meetings. In this phase, we selected some statistics or probability content, and asked pairs or groups of teachers to develop and plan a lesson with the pedagogical assistance of the researcher. In the third phase, we invited teachers to teach the planned lesson to a group of students, making notes that would later be shared with the entire group. The last phase was the communication one. At this stage, teachers shared their experiences with the dynamics of the activities. While discussing and reflecting, teachers themselves listed interventions that were useful to the process of teaching and learning, and those that were less productive.

At the first meeting, participants completed an initial questionnaire, assisting us in understanding the professional background and experiences in statistics teaching and learning, including their experiences with this subject during their teacher education courses. In addition, 
we asked teachers about the approaches they currently utilized in their classrooms. Five further questionnaires with open-ended responses were completed during the following meetings. The objective was to comprehend how teachers understood statistics teaching in comparison to mathematics teaching. Through self-assessment, we attempted to examine which teaching approaches were being used in their classes. Using a process of research and data collection, we sought to know how they felt about teaching statistics. Lastly, we tried to identify the changes that occurred in their teaching practices after participating in this project. All meetings were videotaped.

Information from these questionnaires showed us that the participating teachers did not see statistics as a science, nor did they understand its potential for data analyses. It was considered 'part of mathematics', and teachers referred only to its descriptive nature. This misconception seemed to be provoked by the influence of a procedural approach used in their education at the university. Moore (1992) notes that a basic characteristic of many statistical problems is the lack of a unique mathematical solution. This commonly occurs with realistic statistical problems, which usually begin with a question and end with the presentation of an opinion that may have different degrees of reasonableness. This characteristic of statistical science requires a more flexible, dynamic and empirical approach when teaching.

During the analysis of some teachers' answers and reports to the first two questionnaires, we found aspects of approaches (and even deficiencies) in their education that hindered their teaching, according to Moore (1992). We noted several points: teachers indicated that they were using a procedural approach when teaching statistics, based on the solution of exercises; their academic education in statistics had also been procedural, based on organization of data and formulas; textbooks were used as learning references for students and teaching references for teachers; teachers rarely formed groups to discuss mathematics-related issues; teachers did not have empirical experiences of learning statistics and probability.

Conventional programs providing workshops with deadlines would hardly assist teachers in overcoming these problems. Rather, teachers need to dedicate their time to analyze their obstacles and challenges, and learn how to manage them. By sharing actions, organization, execution and analyses, teachers can give new meanings to the work of teaching, mobilizing various processes and stimulating both cognitive and affective components, allowing their actions to undergo qualitative changes.

In response to our aim of investigating how teachers are influenced by their beliefs when they are planning and implementing statistics lessons, in this paper we analyze as a case study the responses and experiences of two teachers who planned and implemented a statistics lesson. The purpose of this is not to generate a theory but to learn from teachers' practices how their beliefs could influence their teaching approaches. The two teachers were chosen because they both had expressed similar goals for their planned lesson (both wanted students to get experience about law of larger numbers), and also because they illustrated contrasting views and approaches. The teachers chosen had divergent opinions of what is pedagogically important when teaching statistics, although they shared some similarities in the context of their teaching.

We see that to change teachers' attitudes it is important that participants of a professional development process understand sharing as a feature of the qualitative difference between those teachers who plan a collective activity and those who simply execute isolated actions (Vaz, Lopes, \& Silva, 2012). For this reason, we chose to focus on a lesson that was planned collaboratively.

\section{THE CASE STUDIES}

In these case studies, we analyze activities that were planned and later implemented in the classes of two teachers attending the professional development. Those teachers planned and informed their colleagues about their activities, which involved data collection, research and probabilistic simulation.

Looking at the responses of both teachers chosen, we noticed different attitudes about their pedagogical self-confidence. When asked about their confidence to teach probability and statistics, the first teacher, whom we named Rafael, showed a procedural view. He believes that 
learning statistics is about practicing doing exercises: "I have no obstacle on this issue, I just need to practice a bit more". By contrast, the second teacher, whom we named Fernanda, answered: "When I learnt these contents we just practiced through exercises, I believe that I need to learn more about hands-on activities". These different views caught our attention. Even though these teachers' backgrounds to teaching were similar at that time (their previous experience was built around learning through practicing mathematical techniques), they held opposite views about what ideas were important when statistics is taught - mathematical exercises or hands-on lessons.

Rafael has been teaching for 19 years. He was a graduate of an electrical engineering program, he had a pedagogical complement to his degree and obtained a graduate degree in mathematics. He had never attended specialized classes on statistics, even during his undergraduate course. He does not read theoretical articles. His teaching approach aims at mathematical rigor. He has no problem in teaching statistics and does not use technological resources in his class.

Fernanda has been teaching for three years. She was a graduate of a mathematics program, but she had never read anything about statistics teaching. During statistics classes in her undergraduate courses, she filled in tables, made charts manually, and calculated means and standard deviations. She does not feel confident about teaching statistics, and indeed has never done yet, and she plans to teach just for students in the ninth grade (14 years old). She usually uses software programs to teach the four basic mathematical operations, but does not know of any to use in the teaching of statistics.

\subsection{THE EXPERIENCE OF RAFAEL}

The first activity was put together and carried out by Rafael and his partner in the professional development program; it was based on an activity they found on the internet. It consisted of using coins to explore concepts of probability, data collection, the law of large numbers, simulation, observation of a random phenomenon and inference. The pair of teachers applied this coins exercise in two groups of ninth-graders. Although we as researchers suggested to both teachers that they integrate the coins lesson with further work based on roulette wheels, they did not take up our suggestion. This may have happened because they were focused on proving empirically the law of large numbers using their coin activity. Furthermore, the teachers did not have experience with empirical probability lessons, so that at that time they were not secure enough to improve their lessons nor to design new aims for them. We understand that a good pedagogical environment should allow teachers to improve by themselves. Thus, we did not insist that teachers plan their own lesson, since they were not confident for that.

To perform this activity, students were divided into groups. The activity consisted of flipping a coin 60 times and recording each result: heads or tails. After each series of flips, each group verified the number of heads and tails and calculated the percentage of each. Rafael collected data from each group and recorded the total number of heads, tails and flips, entering the results into a table including the percentages. For each group, he asked the students about their overall results.

According to Rafael's report, the students of one classroom understood the activity perfectly and even managed to predict the percent results of future flips. However, the second group of students had great difficulties in understanding the activity, from flipping to data collection. He said:

They calculated using a cellphone calculator, which was the first problem. I had to explain

how to round numbers. Some students, for example, obtained recurring decimals. They

said, "I've got a huge number!" I said, "Use just two decimals." (Rafael)

Although there was an attempt to address statistics through an empirical activity, Rafael was still teaching from an instructional standpoint, rather than from an investigative approach. He did not ask his students about their initial expectations for the results or start by discussing the activity. Rafael's report indicated that from the beginning he sought to demonstrate to the students that after a sequence of flips they would get heads on approximately half of them, and 
tails on the other half. In addition, the teacher's major concern was to explain mathematical content and concepts, such as rounding rules and ratio concepts, rather than discussing the investigative process of collecting data.

Rafael added:

The students from the first classroom didn't have problems with flipping. When I checked the results, all students had flipped the coin 60 times. Results weren't as expected: 25 heads and 35 tails. After that, I wrote on the blackboard the names of the groups, numbering them. Then I asked, "Group 1, what were your results and the percentage?", and wrote the answer on the blackboard. I did the same for each group. Students saw on the blackboard that each group found a different percentage, $48 \%, 52 \%, 42 \%, 53 \%$ and so on. It worked ok with this classroom. But I had problems with the second class. Some students, instead of writing a trace for each result, marked it using an ' $x$ '. When I asked them about their results, the answer was, "35 heads and 45 tails." I said, "But I told you to flip the coin only 60 times. You will have to do it again." Another pair flipped until they got 60 heads, they didn't understand that they should flip only 60 times. Students weren't able to calculate ratio too, they didn't know what ratio meant. In this weak class, one group found 10 heads and 50 tails. I thought this was strange, so I checked how they were flipping the coin. The student held the coin between his fingers leaning against the table and then dropped it, checking later if it was heads or tails. I said, "It is not like that, you have to toss the coin and let it fall by itself, you can't influence the experiment, you will have to do it again." (Rafael)

This report reveals the procedural approach taken by the teacher to the experiment. He had no problems with the first classroom, which seemed to comprise more able students who were used to following his instructions. However, data collection in the second classroom, described by Rafael as undisciplined, was different and difficult. Although students had not faithfully followed the teacher's instructions, he lost several learning opportunities during the communication process because he was focused on results. For example, the ratio results of the pair who flipped the coin more times than necessary would not be so different compared to those who flipped it 60 times. This situation of extra data could have been exploited by the teacher. The percentage of heads in relation to the total flips made by the pair who were trying to obtain 60 heads would probably be even closer to the result Rafael expected. In this case, also, there was no need to discard the experimental results. Lastly, we identify Rafael's purely mathematical treatment of the students who dropped the coin. The teacher expected to have heads in approximately half of the flips. As it didn't happen, Rafael checked if students were doing the right thing according to his point of view.

It does not seem useful to hold fixed ideas about the results when working with a statistical investigation. Usually, during an investigative process, influencing variables are discovered through data collection. In the specific case of the students who were dropping the coin, the teacher rejected the experimental data because he had already predetermined the result. However, he could have explored it in other ways. For example, if the experiment were carried out as the students were doing it, by dropping the coin, would the results be the same as if it were done according to the teacher's instructions? Indeed, what would be the result? Would the coins' mass influence the results? What if, instead of a coin, the students flipped a bottle cap? What would be the probability of each face falling upwards? Another point to consider is that the results presented by the students who dropped the coin are possible (it is part of the sample space), so if the teacher was suspicious he could ask the students to repeat the data collection, assuring himself of the students' neutrality.

With questions like these, students would begin to understand the essence of statistics, which is to investigate rather than to prove. To close the activity, the teacher calculated the flips and the percentage of total heads in relation to the total flips. Finally, he asked the students, "If we flip the coin a million times, how many times would we get heads?" According to the teacher, only one classroom managed to answer this question.

The phenomenon was not fully explored by Rafael in this experiment. This may be due to his traditional pedagogic approach, influenced by his beliefs about teaching statistics, or his initial preparation as an engineer, or maybe by the fact that this activity was found on the internet. As the lesson was not created or re-created by him and his co-worker, this teacher 
faithfully followed each step, presenting to students questions whose answers were predetermined. Using this approach, Rafael perhaps was not pushed to mobilize knowledge in order to achieve the objectives of the activity.

\subsection{THE EXPERIENCE OF FERNANDA}

We make quite different remarks on the activity planned by another teacher, Fernanda, and her colleague, based around the probability of gambling. Students would be divided into pairs and would pick a ball from a bag, write down its color in a table and return the ball to the bag. This procedure would be repeated at least 20 times. Teachers would then use the tabulated results to construct a chart on the board. Meanwhile, they would ask the students which color ball was picked more often. In discussing this plan, we suggested that they take advantage of this activity by introducing gambling issues. The teachers accepted this idea and proposed to bet with students, using play money.

After dividing the class into pairs, Fernanda explained to the students that there were 3 green balls and 7 red balls in the bag. The price paid for a green ball would be R $\$ 16$ (Brazilian Real) and for the red ball R\$ 8 . She asked the class to choose one of the colors to bet on; the other would be the teacher's bet. She explained:

I distribute R \$ 200 in play money to each pair and asked them to choose green or red. If the color they didn't choose was selected, they would pay the stipulated values. Each team received a bag containing 10 balls. The bet would be between students and teacher, so the room should come to a consensus and choose one color. This activity was done with students from $8^{\text {th }}$ grade. When I asked them to choose a color, they hesitated because they didn't know which one offered more chance of winning. Students discussed this question and the view of one student, a girl who did very well in mathematics, was influential. She chose red, which was the color of 7 balls. Some students opposed this, saying they would receive R\$ 16 for the green ball. I knew that I would lose, but I did not interfere. The student's call prevailed. (Fernanda)

Through Fernanda's initial report, we realized that the activity started with an investigative question that enticed students. Who would make more money in the game: the one who chooses the green balls or the red ones? The way the problem was presented led the students to develop a hypothesis. They knew there were seven red balls, but also knew that the green color had a higher value. The teachers who planned this activity had predicted that this would happen. Once students didn't know exactly what would be the answer, they had to negotiate. Then, the anxiety to know the answers and to not lose money led them to carefully observe the results of the game.

Fernanda added:

Before the game started, I explained to the students that they would pick a ball 20 times. I said that, for ethical reasons, they could not cheat. While they were picking, students wrote the picked color on a table. When we were done, students, on their own, multiplied the number of green balls by 16 and the number of red balls by 8 . While checking on the groups, I saw that some had already calculated the money they had to pay. During the activity, I was asking, "Who do you think will win this game?" "Do you think it's a matter of luck?" Most of them said, after the game was over, it was a matter of luck. But a student replied saying that it had to do with statistics. Some students, influenced by this answer, said it was a matter of statistics, but they probably didn't even know what it meant. Many of them had doubts, saying they still believed it was a matter of luck. This happened on the first round, and I obviously lost, once the students had chosen the R \$ 8-balls. So I said: "Let's play again. Who do you think will win this time? Do I have chances to win?" The students said that I did have chances to win. I asked: "Do you believe it?" Students said "Yes" and justified by saying it was a matter of luck. So I said, "Let's play then." (Fernanda)

At this point, the teacher realized she would have to deal with her students' beliefs, so she developed questions that would lead students to modify their beliefs. This is an important step to make students realize that an investigative process should not have preconceived answers. 
Another aspect highlighted in this approach was the emphasis Fernanda gave to observation. After realizing that some students had not changed their initial argument, she decided to play the game once again, trying to convince them that winning the game was not just a matter of luck.

We played it again. Each pair picked 20 times and I obviously lost again. At the end, I asked, "Do you still think it is a matter of luck?" Some students changed their mind and began to argue that the question was about logic, since I had lost twice. I asked, "If we go on playing, do you believe that I will keep losing?" They said I would probably keep losing. So I said, "Let's see, what are the odds?" I took the red balls and asked, "We have 7 balls of this color; there is a total of 10 balls. What is the chance of picking a ball of that color?" That good student replied, "Seventy-percent, teacher." Then everybody said, seventypercent. Then I asked about the other color, and she replied: "Thirty-percent, teacher." (Fernanda)

The investigative process requires reflection about an event's possibilities. Through questions, Fernanda led students to refine their thinking. This does not mean that everyone reached the expected answer; however, they will all be better prepared to deal with such issues in the future, improving their answers about investigative processes.

Modifying beliefs is not a simple process. It takes time and demands understanding the reasons why one believes that way. The mathematical deterministic approach does not help people dealing with these issues in statistics.

Fernanda concluded:

In the end, even picking the ball several times and hearing my questions, some students went home believing that it was a matter of luck. This activity was very interesting because I realized that some students already had this notion of probability, but it was just a few of them. Most of them believed it was a matter of luck. (Fernanda)

Although she had noted that some students still believed in luck, she observed that a different approach helped her to understand her students' cognitive processes. She found this process interesting and was pleased with the changes in her students' thinking. Using experiments in her future classes, her students could also modify their beliefs regarding statistics.

\section{DISCUSSION AND CONCLUSION}

Starting from our initial intention to carry out an analysis of the pedagogical practices of two teachers who planned, implemented and communicated their observations on the development of teaching activities, we realized that throughout the planning stages, they had difficulties and needed to discuss different ways to address the topics.

Developing shared activities in teacher education rarely has an immediate result. Even with some positive results, such as those obtained by Fernanda, we know it will take some time until the process increases participation and trust among professionals, so that they feel safe and prepared to expose their ideas (Souza, 2013). Thus, it could be useful to carry out further experimentation and to document the reflections and feedback of researchers, teacher educators, and co-workers about the way that teachers interact with students during a class. Unfortunately, in this professional development due to teachers' work schedule for the school year we did not have enough time to give teachers feedback and to document changes in their practices.

From the analyses of both activities implemented, we see that encouraging the teacher to lead the process of teaching and learning statistics through open-ended questioning provokes students to explore the quantitative chance of an event. This is an important step that seemed to demystify students' views about luck and the determinism of random events in Fernanda's activity.

We consider that a process of professional development should allow teachers to get involved in the identification of problems and aspects that need to be improved in their approaches. On the other hand, facilitators should be responsible for connecting teachers' difficulties with possible alternatives or solutions. Facilitators need to consider teachers' practice in order to improve teachers' knowledge and educational theory, to provide them with 
opportunities to learn through the inquiry process, and to resolve any problems associated they may have with teaching students.

It is generally accepted in the educational literature that knowledge about the content is an essential component of teachers' competence; no one teaches what one does not know. Teachers need to develop specific statistical and mathematical knowledge in order to give meaning to and evaluate students' unconventional methods; and this should go beyond mathematical training in a particular subject (Henriques \& Oliveira, 2013). Knowledge of content relates to the teacher's ability to analyze how well prepared students are for learning situations, particularly if the students do something unusual or react in an unexpected way. Henriques and Oliveira (2013) suggest that content knowledge includes the ability to justify the processes and representations used, for example, choosing the most appropriate method of measurement for a given set of data, or understanding students' mistakes from the statistical point of view. Developing knowledge about ways of teaching statistics and probability is as important as understanding how to use one's own skills and the historical knowledge produced by science.

Supported by our understanding of the attitudes of teachers Rafael and Fernanda, we consider that their beliefs substantially influence their practice and consequently their approach to planning statistical lessons. When teachers' beliefs are based on the procedural practices of mathematical exercises, they may be less inclined to teach statistics as an investigative science. For this reason, if facilitators wish to improve teachers' attitudes, they may need to carry out a deep analysis of their context, such as community social problems within their school and their own belief system. When teachers plan and implement their own lessons and report back to the group on their teaching experiences, they and the group facilitators have an opportunity to critically reflect on their practice, including identifying gaps in content knowledge.

Thus, as part of collaborative workshop experiences, we recommend that teacher educators provide feedback about the planning and implementation of lessons not only taking teachers' needs into account but also exposing them to new teaching ideas.

\section{REFERENCES}

Begg, A., \& Edwards, R. (1999). Teachers' ideas about teaching statistics. In Proceedings of the 1999 combined conference of the Australian Association for Research in Education and the New Zealand Association for Research in Education, Melbourne, Australia.

[Online: http://www.aare.edu.au/99pap/beg99082.htm].

Henriques, A., \& Oliveira, H. (2013). O conhecimento de futuros professores sobre as investigações estatísticas a partir da análise de episódios em sala de aula. [The knowledge of future teachers about statistics investigations analyzed from episodes in the classroom. In J. Fernandes, F. Viseu, M. Martinho, \& P. Correia (Eds.), Encontro de Probabilidade e Estatística na Escola, 3, 2013, Centro de investigação da Universidade de Minho, pp. 1-13. [Online: http://www.ie.ul.pt/pls/portal/docs/1/423967.pdf]

Imbernón, F. (2010). Formação Continuada de Professores [Continued teachers' development]. Porto Alegre, Brasil: Artmed.

Ireland, S., \& Watson, J. (2009). Building a connection between experimental and theoretical aspects of probability. International Electronic Journal of Mathematics Education, 4(3), 339-370.

Lajoie, S. (1998). Reflections on Statistics: Learning, teaching, and assessment in grades $K-12$. Mahwah, NJ: Lawrence Erlbaum Associates.

Lopes, C. E. (2003). O Conhecimento Profissional dos Professores e Suas Relações com Estatística e Probabilidade na Educação Infantil. [The Professional Knowledge of Teachers and their Relationships with Statistics and Probability in Children's Education]. Ph.D. Thesis, Universidade Estadual de Campinas, Brazil.

Marco, F. (2004). Estudo dos Processos de Resolução de Problema Mediante a Construção de Jogos Computacionais de Matemática no Ensino Fundamental. [Study of Problem Solving Processes by Building Mathematical Computer Games in Elementary School]. Master's Dissertation, Universidade Estadual de Campinas, Brazil. 
Mendonça, L., \& Lopes C. (2013). Modelagem matemática no desenvolvimento profissional dos professores: reflexões e ações. [Mathematical modeling in professional development of teachers: reflections and actions. In: VIII Conferência Nacional Sobre Modelagem na Educação Matemática. Santa Maria, Brazil.

Moore, D. (1992). Teaching statistics as a respectable subject. In: F. Gordon \& S. Gordon (Eds.), Statistics for the twenty-first century (pp. 14-25). Washington, DC: The Mathematical Association of America.

Paparistodemou, E., \& Meletiou-Mavrotheris M. (2008). Developing young students' informal inference skills in data analysis. Statistics Education Research Journal, 7(2), 83-106. [Online: http://iase-web.org/documents/SERJ/SERJ7(2) Paparistodemou.pdf]

Pfannkuch, M. (2005). Probability and statistical inference: How can teachers enable learners to make the connection? In G. Jones (Ed.), Exploring probability in school: Challenges for teaching and learning (pp. 267-294). New York: Springer,.

Pierce, R., \& Chick, H. (2011). Teachers' beliefs about statistics education. In C. Batanero, G. Burrill, \& C. Reading (Eds.), Teaching statistics in school mathematics - Challenges for teaching and teacher education: A joint ICMI/IASE study (pp. 151-162). New York, NY: Springer.

Serradó, A., Azcárate, P., \& Cardeñoso, J. (2006). Analyzing teacher resistance to teach probability in compulsory education. In Proceedings of ICOTS-7 International Conference in Teaching Statistics, Salvador, Bahia, Brazil.

[Online: http://iase-web.org/documents/papers/icots7/2E4 SERR.pdf]

Souza, L. O. (2013). O Desenvolvimento Profissional de Professores em Estatística: Um projeto multidimensional de formação colaborativa. [The Professional Development of Statistics Teachers: A multidimensional project of collaborative training]. Ph.D. Thesis, Universidade Cruzeiro do Sul, São Paulo, Brazil.

Stohl, H. (2005). Probability in teacher education and development. In G. A. Jones (Ed.), Exploring Probability in School: Challenges for teaching and learning (pp. 297-324). New York: Springer.

Vaz, H., Lopes, A., \& Silva, D. (2012). A dimensão colaborativa no movimento de ensinar, aprender e formar-se professor que ensina matemática [The collaborative dimension in teaching, learning and graduating mathematics teachers]. Roteiro, 37(1), 127-146.

LEANDRO DE OLIVEIRA SOUZA

Avenida Nossa Senhora do Rosário, 3863

Tiradentes

Itacoatiara

Amazonas

Brasil

CEP 69103-128 